\title{
¿Qué fue antes, el título o el libro? Análisis genético del proyecto inédito de Juan Ramón Jiménez En la rama del verde limón ${ }^{1}$
}

\author{
Teresa Gómez Trueba \\ Universidad de Valladolid
}

Título: ¿Qué fue antes, el título o el libro? Análisis genético del proyecto inédito de Juan Ramón Jiménez En la rama del verde limón

Resumen: Se propone una reconstrucción del proceso genético de creación del proyecto de libro inédito de Juan Ramón Jiménez En la rama del verde limón, en un doble nivel de microcronología (correcciones internas dentro de cada poema) y macrocronología textual (proceso de creación del conjunto del libro a partir de la ordenación genética del material impreso y original localizado). Tras la constatación de que dicho proyecto se constituía en su integridad con materiales poéticos reciclados de otros libros, se ofrecen una serie de conclusiones acerca de la peculiaridad de la concepción por parte del autor de la Obra, incidiendo en la consideración de la misma como una Obra múltiple, capaz de encerrar dentro de sí numerosas versiones de sí misma.
Title: What Happened First, the Title or the Book? Genetic Analysis of Juan Ramón Jiménez’s Unpublished Project En la rama del verde limón.

Abstract: We propose the reconstruction of the genetic process of the Juan Ramón Jimenez's unpublished book En la rama del verde limón. We focus on a double level: microchronology (internal corrections in a poem) and textual macrochronology (process of creation of the book from the ordination of the printed materials and the original kept). As this project is formed with materials from other books, we offer some conclusions about the particular conception of the writer of the Obra, focusing on the idea of a multiple Work which could have several variants.

1 Este trabajo se ha realizado en el marco de las actividades del proyecto de investigación "Reconstrucción de los libros inéditos de Juan Ramón Jiménez (que quedaron inéditos a la muerte del poeta) a partir de los documentos de sus archivos (Continuación)" (20122014), financiado por el Ministerio de Economía y Competitividad. Ref.: FFI2011-26180. 


\begin{tabular}{l|l}
\hline $\begin{array}{l}\text { Palabras clave: Juan Ramón Jiménez, En la } \\
\text { rama del verde limón, Crítica Genética, Borra- } \\
\text { dores, Inéditos. }\end{array}$ & $\begin{array}{l}\text { Key words: Juan Ramón Jiménez, En la rama } \\
\text { del verde limón, Genetic Criticism, Drafts, } \\
\text { Unpublished. }\end{array}$ \\
\hline Fecha de recepción: $27 / 1 / 2014$. & Date of Receipt: $27 / 1 / 2014$. \\
\hline $\begin{array}{l}\text { Fecha de aceptación: } 11 / 3 / 2014 . \\
\text { Date of Approval: } 11 / 3 / 2014 .\end{array}$
\end{tabular}

\section{LA ADECUACIÓN DE LA CRÍTICA GENÉTICA PARA EL ESTUDIO DE LA OBRA INÉDITA DE JUAN RAMÓN JimÉNEZ}

Tras años de incesable goteo de inéditos, de aparición de ediciones que reconstruyen, con mejor o peor fortuna, los proyectos de libros de Juan Ramón Jiménez, creando un estado editorial complejo, laberíntico y problemático, se han empezado a elevar las voces críticas que reclaman un necesario consenso metodológico a la hora de dar a conocer el corpus de sus proyectos inéditos. Y, más aún, aquellas que denuncian la inconveniencia de seguir reconstruyéndolos y editándolos como si fueran auténticos libros del poeta. En este sentido deben verse los recientes trabajos de Silvera, Blasco o León Liquete ${ }^{2}$. Comparto con ellos la opinión de que no deberíamos obcecarnos en reconstruir y editar cada uno de los proyectos de libro que él diseñó, porque tales proyectos remiten por lo general a un conjunto de indicaciones e índices incompletos y contradictorios y a una serie de borradores más o menos elaborados, pero nunca concluidos. El resultado de tales reconstrucciones es siempre una versión del libro elegida por el editor, entre otras muchas posibles que, de igual modo, podrían desprenderse de los confusos planes editoriales del poeta. A partir de estas inconveniencias y de los problemáticos resultados obtenidos en la edición de inéditos juanramonianos (publicaciones que se solapan y contradicen, aparición de supuestos inéditos que en realidad no lo son, publicación de

2 Paco Silvera, Copérnico y Juan Ramón Jiménez. Crisis de un paradigma, Vigo, Academia del Hispanismo, 2008; Carlos León Liquete, Los puntos sobre las jotas. La ecdótica ante los archivos de un poeta contemporáneo: Juan Ramón Jiménez, Valladolid, Universidad de Valladolid, 2010; Javier Blasco, Poética de la escritura / El taller del poeta. Ensayo de crítica genética (Juan Ramón Jiménez, Francisco Pino y Claudio Rodríguez), Valladolid, Cátedra Miguel Delibes, 2011. 
supuestos textos terminados que tan sólo son borradores o ante-textos...), creo que efectivamente, tal y como sostienen los críticos arriba citados, sólo deberíamos considerar como obras de Juan Ramón aquellos libros o poemas sueltos que el poeta publicó en vida.

Ahora bien, el escepticismo que actualmente albergan algunos estudiosos de la obra juanramoniana acerca de la posibilidad de editar los libros inéditos no debería hacernos olvidar la gran importancia que el autor les otorgaba, ni el gran interés que, desde muchos puntos de vista, estos tienen para estudiosos y lectores. Como bien ha advertido Varo Zafra, en los estudios juanramonianos es necesario distinguir entre lo que el poeta llamaba la Obra y las obras concretas del poeta ${ }^{3}$. Ambas reclaman estudios y metodologías diferentes, pero no creo que sean excluyentes. Las segundas hacen referencia a los libros que el autor publicó y autorizó en vida, y la crítica textual tradicional ofrece, como en el caso de cualquier otro autor, los instrumentos y la metodología adecuados para su edición y análisis. Lo proyectos inéditos, en cambio, forman parte de la primera - la Obra- y abordados por la crítica con una metodología adecuada son importantísimos no sólo para tomar conciencia de la magnitud de lo escrito por nuestro autor, sino, sobre todo, de cara a conocer mejor su original concepción de la creación poética (su peculiar idea de una Obra en marcha, múltiple y total). La forma en la que Juan Ramón concebía la organización de la totalidad de su Obra es un asunto interesante por sí mismo (y no sólo con vistas a trabajar en una posible edición de su Obra completa), pues creo que nos dice mucho de su poética, de la forma que tenía el moguereño de entender la poesía. No en balde, recordemos que este autor empleó tanto o más tiempo y esfuerzo en diseñar y planificar la forma en la que se debería publicar su

3 "La raíz del problema, en nuestra opinión, está en la dialéctica no resuelta entre Obra y obras en la poesía de Juan Ramón. [...] El campo generado por la relación antitética entre multiplicidad y unidad de la obra juanramoniana plantea al editor la dificultad de articular los numerosos libros y proyectos de libros en un conjunto sistemático coherente, esto es, unitario, al que, sin embargo, se opone la realidad de los hechos: la sucesión interminable de proyectos, la reformulación de los planes editoriales, el continuo deslizamiento de poemas y prosas -con sus numerosas variantes y variaciones-, títulos e índices en la inquieta mente del autor" (Juan Varo Zafra, Juan Ramón Jiménez en el Archivo Histórico Nacional, Bonanza, Vigo, Academia del Hispanismo, 2011, I, p. 23). 
Obra (el número de índices de libros y de volúmenes de libros que se conserva en los archivos del poeta es realmente sorprendente), que en la escritura de los textos concretos - poemas o prosas- que la componían. Entiendo que no debemos editar como auténticos libros del poeta los proyectos inéditos, pero sí deberíamos estudiarlos, analizar su contenido, la evolución de su diseño a lo largo de los años, su permanencia o no permanencia en los planes editoriales del autor y el porqué de esos constantes cambios de decisión.

En este artículo me propongo analizar (no reconstruir, ni editar) un proyecto juanramoniano nunca antes atendido por sus críticos y editores, En la rama del verde limón. Para tal fin, y dado que no es mi intención reconstruir un libro inédito, que en realidad nunca fue concluido por su autor, la ecdótica tradicional se revela como metodología inadecuada, mientras que la Crítica Genética nos proporciona una perspectiva y unos instrumentos mucho más eficaces. Como se sabe, el objetivo de esta ya no es la reconstrucción de un supuesto texto original a partir de la localización y cotejo de un determinado número de testimonios, sino la reconstrucción del proceso genético de creación de una determinada obra a partir de los materiales localizados al respecto (notas, borradores, copias, pruebas de imprenta, ejemplares corregidos, etc.)

En un pionero trabajo del año 1987, reelaborado en 1989, Eduard Márquez ya destacaba la adecuación entre esta disciplina y la peculiaridad de la Obra de Juan Ramón Jiménez. Teniendo en cuenta la conocida concepción de "Obra en marcha" que tan bien define a la juanramoniana y que el propio autor se cuidó de advertir a sus posibles editores póstumos una y otra vez, una obra "que tiene en su propio dinamismo su más honda razón de ser", Márquez demuestra lo adecuado que es para el estudio y edición de la misma una "crítica textual en marcha", como, sin duda, lo es la Genética ${ }^{4}$.

4 Eduard Márquez, "Apuntes metodológicos para la edición genética de Juan Ramón Jiménez”, Anthropos. Juan Ramón Jiménez, la obra como construcción poética de la realidad (nueva edición), 7, (1989), pp. XIII-XV (p. XV). La interesante recomendación de Márquez no parece haber tenido durante años ningún seguimiento por parte de los estudiosos y editores del poeta. No obstante los miembros del equipo de investigación "Reconstrucción de los libros de poesía de Juan Ramón Jiménez (que quedaron inéditos a la muerte del poeta) a partir de los documentos de sus archivos" (Plan Nacional de I+D) (http://www.ineditosjrj.es/) nos propusimos estudiar todos los libros inéditos que Juan Ramón Jiménez anunció en la Segunda antolojía poética 
A partir de ahí, y siguiendo esta interesante línea de trabajo que se nos proponía entonces, pretendo en este artículo dar a conocer y analizar los materiales relativos al proyecto inédito En la rama del verde limón. Parto, en primer lugar, del acopio del material relativo a este libro inédito, en un doble sentido: recopilación de impresos y manuscritos. La recopilación del material impreso supone en este caso la localización de las entregas parciales del proyecto en revistas en vida del autor, ya que nunca lo publicó ni total ni parcialmente en forma de libro. Respecto a los originales, hemos de advertir una vez más la precaria catalogación que presentan los fondos juanramonianos en los archivos que los albergan (principalmente el Archivo Histórico Nacional de Madrid ${ }^{5}$ y la Sala Zenobia-Juan Ramón Jiménez de la Universidad de Puerto Rico) y la falta de garantías en este sentido a la hora de poder asegurar que conocemos la totalidad de los materiales originales relativos al proyecto que vamos a analizar. Para el trabajo que ahora presento he limitado mi investigación al AHN y, dentro de este, a los originales hallados en un sobre que, en la catalogación del archivo, se relaciona con el proyecto inédito En la rama del verde limón ${ }^{6}$. Pero, naturalmente, no descarto que en este o en otro archivo, puedan existir otros documentos relacionados con el mismo.

En segundo lugar, he ordenado, transcrito y descrito los materiales localizados, lo que ocupa una parte importante de este trabajo. El análisis material de los autógrafos (soporte, letra, útiles de escritura...) se nos revelará como especialmente fructífero en este caso.

En una tercera fase de mi trabajo, a partir de los materiales localizados y previamente descritos, elaboro una clasificación genética de los mismos en un doble sentido. Por un lado, intento reconstruir de forma lógica las operaciones internas dentro de cada texto (tachaduras, sustituciones, añadidos, variantes alternativas), que en el caso de este proyecto son bastante

(1922), primero, y en Poesía (1923) y Belleza (1923), después, a partir de estas premisas metodológicas que nos posibilita la Crítica Genética. Véanse Juan Varo Zafra, op. cit.; Paco Silvera, Juan Ramón Jiménez en el Archivo Histórico Nacional. Monumento de amor, Ornato, Ellos, Vigo, Academia del Hispanismo, II, 2012; y Teresa Gómez Trueba, Juan Ramón Jiménez en el Archivo Histórico Nacional. Poemas impersonales, Vigo, Academia del Hispanismo, III, 2012.

5 A partir de ahora AHN.

6 Ma Teresa de la Peña y Natividad Moreno, Catálogo de los fondos manuscritos de Juan Ramón Jiménez, Madrid, Ministerio de Cultura, 1980, p. 22. 
escasas. Por otro lado, más relevante para el caso que nos ocupa, reconstruyo el proceso de creación del libro a partir de la ordenación genética del material impreso y original localizado. En definitiva, intento en esta tercera fase de mi trabajo desgranar el proceso de creación del proyecto inédito y no concluido En la rama del verde limón, en un doble sentido de microcronología y macrocronología textual.

Por último, y tras el análisis de lo que podríamos considerar un dossier genético, ofrezco una serie de conclusiones que creo iluminan algo más la peculiar concepción juanramoniana de la Obra y, de paso, de la creación poética.

2. LOCALIZACIÓN, TRANSCRIPCIÓN Y DESCRIPCIÓN DE LOS MATERIALES DESTINADOS A EN LA RAMA DEL VERDE LIMÓN

\subsection{Anuncios y publicaciones parciales del libro}

Primero hay que advertir que en el caso de En la rama del verde limón, y a diferencia de otros muchos proyectos de libros inéditos contemporáneos de este, Juan Ramón nunca lo representó en las diferentes antologías que fue publicando para dar a conocer su obra inédita, tales como Poesías escojidas (1917), Segunda antolojía poética (1922), Poesía (1923) o Belleza (1923). Sin embargo, sí que anunció y publicó parcialmente el libro en las páginas de alguna revista. Concretamente, el autor publica una selección de poemas de En la rama del verde limón en tres ocasiones: en la revista España, no 284, el 9 de octubre de 1920, p. 13 (donde se incluyen los poemas: "Alrededor de la copa...", "Me escondí en el arbusto...”, "He venido...”, “¡Allá va el olor...” y "No me mirarán diciendo...”); en la revista Horizonte, no 3, el 15 de diciembre de 1922, p. 1 (donde se incluye el poema "Mis ojos abiertos..."); y en el cuaderno 30 de Unidad (Madrid, León Sánchez Cuesta, 1925) (donde se incluye el poema "Álamo blanco"). Este tipo de publicaciones parciales en revistas o cuadernos, muy habituales en la bibliografía juanramoniana de los años veinte y treinta, eran concebidas por el poeta a modo de anuncio de los libros en los que estaba trabajando y que presumiblemente daría a la imprenta en un futu- 
ro no lejano ${ }^{7}$. No obstante, como ocurre con la mayor parte de los proyectos de libros inéditos de Juan Ramón Jiménez, lo poco que este dio a conocer en vida no nos permite hacernos una idea de la totalidad del libro en cuestión, de su posible peculiaridad formal o temática en comparación con otros de sus títulos.

Por otro lado, en las conversaciones que Juan Ramón y Juan Guerrero Ruiz mantuvieron a diario, en las que se hablaba continuamente de los proyectos editoriales del autor, solamente una vez se menciona En la rama del verde limón:

\begin{abstract}
Juan Ramón, tristemente, me dice que él no se encuentra bien, no tiene la vitalidad necesaria para trabajar como hace veinte ańos y ha de ir a lo más esencial, que es publicar estos volúmenes de su obra; si viviera para verla publicada, que no lo espera, entonces le gustaría mucho destacar algunos libros en ediciones especiales o hacer libros pequeños, como El Niño, En la rama del verde limón, El Mar, o una nueva antología completamente distinta ${ }^{8}$.
\end{abstract}

Curiosamente, esa alusión se encuentra en una conversación mantenida el 11 de septiembre de 1935. Es decir, 15 años después de proyectar el libro, Juan Ramón sigue teniendo cierta consideración por él. En cualquier caso, como ahora veremos, y como ocurría en muchísimas ocasiones, esa supuesta estima del autor por el proyectado libro no se corresponde con la realidad que encontramos en los archivos. En el caso que nos ocupa más pobre de lo esperado.

7 Naturalmente, más poemas de los adscritos en un momento dado por Juan Ramón al libro En la rama del verde limón fueron publicados en otras ocasiones por el poeta. Pero solamente me interesan ahora los casos en los que lo hicieron bajo la adscripción a En la rama del verde limón. Dado que mi objetivo en este trabajo es trazar el proceso genético de creación del libro En la rama del verde limón, tampoco me interesarían las posibles reconstrucciones y ediciones póstumas del libro, aunque, en este caso, tampoco las hay. Solamente se ha publicado un poema, titulado "Adviento", junto a un dibujo del poeta, con la adscripción a En la rama del verde limón, y fechado en 1919. Se trata de un folleto de cuatro páginas editado por los herederos del autor, a modo de felicitación navideña, en 1960.

8 Juan Guerrero Ruiz, Juan Ramón de viva voz (1932-1936), Valencia, Pre-textos, 1999, II, p. 327. 


\title{
2.2. Originales conservados en el $A H N$
}

En el sobre 106 del AHN, se conservan 29 papeles adscritos, según la catalogación del archivo, al proyecto titulado En la rama del verde limón 9 . Entre los 29 papeles hay muchos manuscritos y otros mecanografiados con anotaciones manuscritas. Por otro lado, junto a los poemas destinados al libro, encontramos también numerosos documentos referidos a su diseño y estructura. Concretamente, 17 contienen diseños de portadas, índices o anotaciones sobre el libro. En el primero de los papeles del sobre encontramos este diseńo de portada ${ }^{10}$ :

\author{
AHN, 106/1. Borrador mecanografiado. \\ El jirasol y la espada \\ $\mathrm{V}$ \\ Juan Ramón Jiménez \\ Jardín menor \\ I \\ En la rama del verde limón \\ $<($ ¿o \\ El pajarito verde?)> \\ Juan Ramón Jiménez \\ Y Zenobia Camprubí de Jiménez \\ Editores \\ De su propia obra \\ Mactrict \\ El mundo
}

9 Respecto al proceso a través del cual se llevó a cabo la ordenación de los fondos juanramonianos en el AHN, puede verse el libro de Carlos León Liquete, op. cit., pp. 46 y ss. La ordenación de estos papeles no fue en exclusiva debida a Juan Ramón y en la actual distribución por carpetas y sobres hubo en distintos momentos intervención de manos ajenas al poeta, pero lo cierto es que, en el caso que nos ocupa, todos los documentos agrupados en el sobre 106 tienen inconfundiblemente relación con el proyecto.

10 En la trascripción diplomática de los poemas me valgo de los siguientes símbolos: [...] espacio en blanco; Palabras tachadas; \{\} otra opción apuntada entre líneas; <> palabras manuscritas añadidas al texto mecanografiado. 
A partir de los datos referidos en esta portada, deducimos que el proyecto En la rama del verde limón era uno de los libros pensados para formar la serie Jardin menor, que a su vez formaba parte de la serie mayor El jirasol y la espada. En otro papel conservado en el mismo sobre tenemos más datos acerca de todo esto; así, en el papel AHN, 106/9, encontramos bajo el título general de El jirasol y la espada y la indicación de "Series mías" una larga lista de títulos de libros, en la que el primero que figura es En la rama del verde limón.

Pero además de la portada, Juan Ramón diseñó también las primeras páginas del libro. Sabemos así que las páginas 1, 2, 3, 4, 6 y 9 deberían ir en blanco. En la 5, bajo el título general de la serie El jirasol y la espada, anota: "Autores, traductores y editores: Zenobia Camprubí de Jiménez y Juan Ramón Jiménez". Deducimos entonces que en El jirasol y la espada no sólo se publicarían poemas de Juan Ramón Jiménez sino también traducciones y ediciones de otros autores. En la 7 se repetiría el título, y en la 8 aparece la información relativa a esos otros autores y poemas que serían editados dentro del proyecto El jirasol y la espada (que, no lo olvidemos, contiene en su interior En la rama del verde limón). En esta hoja (AHN, $106 / 10)$, que correspondería a la página 8 del diseño del libro, podemos leer:
I: - John M. Synge: Jinetes hacia el mar.
II.- Charles Van Lerberghe: Husmeadores.
III.- William Butler Yeats: La Condesa Catalina.
IV.- Teixeira de Pascoaes: Verbo oscuro.
V.- Juan Ramón Jiménez: En la rama del verde limón.

En la página 10 iría un "Dibujo de esta serie”; en la 11 de nuevo la reproducción de la portada; en la 12, el copyright, fechado en 1919; y en la 13, de nuevo el título del libro. Bajo un índice de poemas (AHN, 106/3), Juan Ramón anota todavía en la misma hoja una serie de indicaciones referentes a la constitución del volumen:

Primero, el pliego de portadillas

$\mathrm{Al}$ frente, la nota sobre estos libros. 
Cada canción, cuatro pájinas: una, el título, dos la poesía, y una, un adorno.

Índice: cuatro pájinas

Papel grueso.

Vemos, por tanto, que Juan Ramón puso en este caso especial cuidado en diseñar los aspectos materiales. No es esta la única ocasión en la que diseñó la portada y primeras páginas de un libro en proyecto. En los proyectos editoriales de los años veinte esta práctica llegó a ser algo bastante habitual. Pero, en este caso, el poeta parece ir aún más lejos que en otras ocasiones, ya que el documento AHN, 106/29, contiene una amplia hoja doblada simulando ser la cubierta, en la que seguramente el poeta guardaría el resto de los documentos conservados. Es decir, Juan Ramón, en esta ocasión, pareció entretenerse también en construir materialmente el libro.

Por otro lado, excepto algunas notas apuntadas en papeles de menor tamańo, el material conservado en este sobre, todo él relativo al proyecto En la rama del verde limón, se contiene en hojas que presentan una gran uniformidad en cuanto al tamaño y tipo de papel y letra, lo que no sólo da cierto aspecto de madurez al proyecto, sino que le confiere el aspecto de un auténtico libro (de nuevo, en el sentido material del término) a ojos del investigador.

Dicho todo esto, hasta aquí las cosas podrían resultar sencillas de cara a una posible reconstrucción y edición del inédito. Pero, como suele ocurrir en todos los proyectos inéditos de Juan Ramón Jiménez, junto a estos documentos, que, a juzgar por la letra y otras cuestiones materiales, parecen haber sido escritos en una misma fase redaccional, se conservan también en el mismo sobre otras notas referidas al mismo proyecto, pero que apuntan hacia posibilidades alternativas y que, seguramente, fueron escritas en otro momento. En una nota manuscrita (AHN, 106/3) se apunta la posibilidad de que El pajarito verde sea un subtítulo de En la rama del verde limón y no un título alternativo a este. En otros papeles anota como posibles subtítulos para En la rama del verde limón, otros diferentes: Figuraciones (AHN, 106/4) o Apuntes (AHN, 106/5). En otra hoja (AHN, 106/sin numerar) fecha el proyecto en "19[...]-1920", lo que discrepa de la fecha de 1919 que figuraba en algunas de las notas transcritas más arriba. 
Además de los papeles que contienen el diseño del libro, encontramos alguno referido al contenido del mismo. Entre los índices que se conservan en el sobre 106, destaca por su amplitud el que incluye el documento AHN, 106/3, donde podemos leer:

En la rama del verde limón

1

Alrededor de la copa

Me meto en el arbusto

He venido

¡Allá va el olor!

Morado y verde limón

Arriba canta el pájaro

No me mirarán diciendo

No recuerdo

En estas redes finas

Hojita verde sin sol

Como vivo en la llama

Adónde, nubes del ocaso

Cuando yo pasé por la noche

Espera, ratito de oro

Cuando tardas en salir

Color que, un momento, el humo

¡Llevarme a la mar

Pero existen más índices relativos al contenido del libro y, como suele ocurrir en los proyectos juanramonianos, estos no son en absoluto coincidentes. $\mathrm{Ni}$ siquiera uno completa al otro, sino que ofrecen más bien una constitución alternativa del conjunto de poemas. Así, en el documento AHN, 106/16, y bajo la habitual indicación de "En la rama", anota el poeta: "Todas las canciones de El pajarito verde"; y debajo: "En nuevas ediciones, añadir las nuevas de $E l$ p. o., pero con un orden caprichoso". En otro diseño de la portada (AHN, 106/13), bajo el título anota "Primera edición". A partir de estas indicaciones, deducimos que Juan Ramón pensó en algún momento en hacer más de una edición del libro y, lo que es más interesante, actualizar su contenido con nuevos poemas en las sucesivas ediciones, lo que, sin duda, responde a su particular concepción de la "Obra en marcha". 
La mayor parte de los editores juanramonianos, al encontrarnos con tentadoras indicaciones del poeta como las que yo acabo de transcribir, nos hemos lanzado a una frenética labor de reconstrucción de los proyectos inéditos, localizando por aquí y por allá los poemas que el autor anota en cada uno de los índices, completando así un libro que el autor diseñó, pero que en realidad no llegó a escribir. Como ya he dejado claro, no es ahora esta mi intención, pues no me interesa tanto lo que el autor pudo o quiso haber hecho, sino lo que realmente hizo, a juzgar por el material realmente conservado.

Pues bien, en el interior de ese libro, diseñado con tanta minuciosidad y cuidado, hallamos un contenido bastante decepcionante (no por la calidad de los textos, naturalmente, sino por su cantidad). Apenas once poemas (frente a los 17 anotados en el índice que acabo de transcribir) conforman En la rama de verde limón. Once poemas que, todo sea dicho, y como más abajo veremos, ni son inéditos, ni fueron originalmente escritos para conformar el título que ahora nos ocupa.

De los once poemas, diez son borradores mecanografiados con anotaciones manuscritas, que a continuación paso a transcribir:

AHN, 106/18. Borrador mecanografiado con anotaciones manuscritas.

EN LA RAMA DE VERDE LIMÓN

Pájaro del sueño rosa,

¿de dónde eres, dónde estas?

$<$ Cómo $>-$ ¿Por dónde entra, ojos cerrados,

en nuestra honda oscuridad?-

Pájaro del sueño dulce,

¿quién te llama, a donde vas?

$<($ La frente pensativa: II: Canciones $)>$

$<$ De «La frente pensativa».>

AHN, 106/19. Borrador mecanografiado con anotaciones manuscritas. La anotación manuscrita de un "I", seguido de un signo de interrogación, al frente del poema parece indicar las dudas del autor acerca de ponerlo en primer lugar. La anotación manuscrita "Esplá", referida sin duda 
al conocido compositor español Oscar Esplá (Alicante, 1886 - Madrid, 1976), uno de los artistas mencionados en los índices de Españoles de tres mundos, y que debió de surgir de alguna asociación producida en la mente del poeta al releer su texto, se repite en otro de los poemas destinados al libro, concretamente el que comienza "Alrededor de la copa...". En el mismo sobre 106 se conserva otra versión también mecanografiada de este poema (AHN, 106/8), pero con el título "El pajarito verde" y con la única anotación manuscrita: "o 13”, en el margen superior derecho. El poema se publicó en la revista España, no 284, el 9 de octubre de 1920, p. 13, en idéntica versión.

\section{EN LA RAMA DEL VERDE LIMÓN}

$<\mathrm{I}$ ?>

He venido.

Pero allí se quedó mi llanto,

a la orilla del mar,

llorando.

He venido.

Pero no os serviré de nada, porque allí se quedó

mi alma.

He venido.

Pero no me llaméis hermano, que mi alma está allí, llorando.

$<($ La corriente infinita $)>$

$<$ Esplá $>$

$<$ De «La corriente infinita.»>

AHN, 106/20. Borrador mecanografiado con anotaciones manuscritas. Las anotaciones manuscritas sobre el poema parecen indicar que el autor 
pensó en él para cerrar el libro. Dicho libro se publicó en la revista Espa$\tilde{n} a, \mathrm{n}^{\circ} 284$, el 9 de octubre de 1920, p. 13, sin la variante del verso 4, y sin la referencia al escritor irlandés James Sthepens (Dublín, 1880 - Londres, 1950).

\section{EN LA RAMA DEL VERDE LIMÓN}

$<\mathrm{y}>$

$$
\text { (James Stephens) }
$$

No me mirarán diciendo:

"¿Qué eres?»;

sino sin curiosidad

y dulcemente.

Porque yo seré también de $\quad<$ (de ellos, $>$

los quietos;

y ya no tendré difíciles

los pensamientos.

Mis ojos serán, serenos,

los suyos;

los miraré sin preguntas,

uno en lo uno.

$<($ Luz de la atención) $>$

$<$ Fin $>$

<«Luz de la atención»>

AHN, 106/21. Borrador mecanografiado con anotaciones manuscritas. El poema está recortado y pegado sobre un papel más grande donde aparecen otras indicaciones manuscritas. La anotación final también parece reflejar en este caso las dudas del poeta acerca de poner este poema al final del libro, a modo de epílogo. 
$<$ En la rama del verde limón>

MUYTARDE

Piando a la luz, asciende el pájaro

por las doradas copas;

y su pío resuena

en la sombra de abajo,

como en un pozo hondo

de verdor y silencio.

Él se sume en su sueño,

atravesando luces májicas.

Mi corazón es sombra

del fondo resonante.

$<($ La realidad invisible: $y$ III) $>$

$<$ De

«La realidad invisible».)>

$$
<(\text { Epílogo? })>
$$

AHN, 106/22. Borrador mecanografiado con anotaciones manuscritas.

EN LA RAMA DEL VERDE LIMÓN

$<$ Nostaljia $>$

¡Hojita verde con sol,

tú sintetizas mi afán;

afán de gozarlo todo,

de hacerme en todo inmortal!

$<($ Piedra y cielo: $y$ III) $>$

$<$ De

«Piedra y cielo».>

AHN, 106/23. Borrador mecanografiado con anotaciones manuscritas. 


\section{EN LA RAMA DEL VERDE LIMÓN}

Verde es la niña; tiene

verdes ojos, pelo verde.

En el verde aire viene;

la tierra se pone verde.

En el mar verde viene;

el cielo se pone verde.

En mi alma encuentra $<\{\mathrm{Mi}$ alma le abre $\}>$ siempre

una puertecita verde.

$<$ (La frente pensativa: II:

Canciones) $>$

$<$ De «La frente pensativa».>

AHN, 106/24. Borrador mecanografiado con anotaciones manuscritas. En el sobre 106 falta la hoja en la que termina el poema y en la que, seguramente, el poeta indicó el libro del que procedía. No obstante, como ya hemos anotado más arriba, este poema se publicó en la revista Horizonte ( $\mathrm{n}^{\circ} 3$, el 15 de diciembre de 1922, p. 1), como un anticipo del libro En la rama del verde limón, en su versión completa. Los versos que faltan en el borrador que ahora paso a transcribir, según la versión de Horizonte, serían estos: “Llevadme a la mar, / a ver si me duermo". Asimismo, en esta versión Juan Ramón indicaba que el poema procedía del libro El vencedor oculto. En la versión de Horizonte existen además importantes variantes respecto al original del archivo que aquí se transcribe: en el verso 9, dice "de llanto y deseo". En el verso 10: "Un mar sin consuelo". Y entre la estrofa $4^{\circ}$ y $5^{\circ} \mathrm{del}$ original del AHN, hay otra en la versión de Horizonte: "No imitan los besos, / ni el dulce cantar, / la ola y el viento". Creo que la versión de Horizonte, mucho más elaborada, es posterior a la que encontramos en el sobre 106 del AHN. 


\section{EN LA RAMA DEL VERDE LIMÓN}

¡Mis ojos abiertos!

¡Llevadme a la mar,

a ver si me duermo!

¡Mientras esté lejos, no se han de cerrar mis ojos abiertos!

¡Llorarán recuerdos, hasta hacer un mar de llanto y de anhelo!

¡Un mar de deseo, que me ha de llevar al desvelo eterno!

¡La ola y el viento!

$$
<(\text { Sigue })>
$$

AHN, 106/sin numeración. Original mecanografiado con anotaciones manuscritas. La anotación manuscrita de una " $\mathrm{P}$ " sobre este poema y el siguiente pudiera indicar que Juan Ramón los seleccionó en una presumible revisión y relectura de los textos para su libro antológico Poesía (1923), donde efectivamente fueron publicados.

$<$ En la rama del verde limón.> ENTRETIEMPO

$$
<\text { P. }>
$$

¡Espera, ratito de oro, que quiero gozarte allí; espera, ratito de oro, que quiero gozarte aquí!

$$
<\text { (Entretiempo: 1: }
$$


Fresco y sol)>

AHN, 106/26. Borrador mecanografiado con anotaciones manuscritas.

EN LA RAMA DEL VERDE LIMÓN

$$
<\text { P. }>
$$

En estas redes finas,

cómo se mece el alma,

¡ay, primavera mía!

Ramas de sauces, aún

sólo con luz de brote;

¡ay, fresca $<\{($ leve $)\}>$ juventud!

Almendros, aún con alba,

solo, de candor rosa;

¡ay, divina mañana!

$<($ Entretiempo: 1:

Fresco y sol)>

$<$ De «Entretiempo».>

AHN, 106/27. Borrador mecanografiado con anotaciones manuscritas. El poema se publicó en España, no 284, el 9 de octubre de 1920, p. 13, en idéntica versión.

\section{EN LA RAMA DEL VERDE LIMÓN}

Alrededor de la copa

del árbol alto,

mis sueños están volando.

Son palomas, coronadas

de luces puras, 
que, al volar, derraman músicas.

¡Cómo entran, cómo salen

del árbol solo!

¡Cómo me enredan en oro!

$$
<(\text { La torre abierta })>
$$

$<$ Esplá $>$

$<$ De «La torre abierta».>

En el mismo sobre 106, encontramos también un poema más, el que comienza "Me escondí en el arbusto..." (AHN, 106/7). Se trata de un recorte de texto impreso pegado sobre otra hoja y que no contiene la habitual indicación de "En la rama del verde limón". No obstante, es de suponer, si tenemos en cuenta uno de los índices arriba transcritos (AHN, 106/3), así como el adelanto que hizo el autor de En la rama del verde limón en la revista España, que también este poema estaba destinado al libro y que fue el mismo Juan Ramón quien guardó el recorte junto al resto de los originales.

AHN, 106/7. Recorte de texto impreso, procedente de la edición de la revista España, no 284, el 9 de octubre de 1920, p. 13, pegado sobre otra hoja y con una tachadura manuscrita.

z

Me escondí en el arbusto.

¡Ay, como olía,

cómo olía a la vida!

Me oculté en la corriente.

¡Ay, cómo huía,

cómo huía a la vida! 


\section{ANÁlisis genÉtico DE los materiales transCritos}

Es necesario detenernos en algunas cuestiones que tienen que ver con la materialidad de los documentos hallados en el sobre 106. Ya hemos hablado de cierta uniformidad en el tipo de papel y en el intento juanramoniano de construir materialmente el libro. Por otro lado, hay que notar que los papeles que contienen información relativa al diseño material del libro o a su constitución interna están manuscritos, mientras que los 11 poemas transcritos son borradores mecanografiados con anotaciones manuscritas (a excepción del último, que es un recorte de texto impreso). León Liquete establece una interesante clasificación de la caligrafía juanramoniana a partir de la cronología: "se pueden establecer, al menos, tres tipos básicos de letras manuscritas del poeta, que corresponden a otros tantos momentos de evolución de su obra" ${ }^{11}$. En todos los documentos manuscritos o con anotaciones manuscritas referidos a En la rama del verde limón encontramos el tipo de "letra 3", según la clasificación de León Liquete, una letra ligada y arábiga, reconocida como la caligrafía más característica del poeta, que aparece en su obra en torno al Diario de un poeta recién casado (1916).

Pero a pesar de esta uniformidad en la caligrafía, es cierto que en las copias de los poemas mecanografiados con anotaciones manuscritas que hemos analizado es posible distinguir dos fases de redacción diferentes ${ }^{12}$ : una primera copia en limpio del poema a máquina precedida del título "En la rama del verde limón", también escrito a máquina y, por tanto, en esa primera fase; y una segunda fase en la que el poeta relee el poema, incorpora pequeñas correcciones manuscritas y anota, también de su puño y letra, el título del libro del que procede. Sólo en tres ocasiones el autor

11 Carlos León Liquete, La perdida. Análisis material de carpetas y proyectos en los archivos de Juan Ramón Jiménez, Valladolid, Difácil, pp. 51 y ss., en prensa. Aprovecho para agradecer al autor el acceso al original de este trabajo antes de su publicación.

12 En las conversaciones con Ricardo Gullón declaró el autor acerca de su sistema corrector: "escribo siempre de un tirón, a lápiz, luego lo dicto o lo pone Zenobia a máquina, y lo veo objetivado, fuera de mí. Entonces sí lo corrijo despacio, pero después, una vez que lo dejo, ya no me ocupo de él: si años más tarde lo releo tal vez cambio un adjetivo, una palabra, si en la nueva lectura el cambio se impone por sí" (Ricardo Gullón, Conversaciones con Juan Ramón Jiménez, Madrid, Taurus, 1958, pp. 80-81). 
no volvió a copiar el poema expresamente para destinarlo a En la rama del verde limón: se trata de los borradores AHN, 106/21 ("Muy tarde"); AHN, 106/25 (“¡Espera, ratito de oro...!”) y AHN, 106/7 (“Me escondí en el arbusto...”). En el primer caso, el autor recorta una copia mecanografiada del poema y lo pega sobre otra hoja, en la que anota manuscrito el título "En la rama del verde limón” y el título del libro del que procedía el texto en cuestión. En el segundo, anota sobre la indicación del título del que tomó el poema, "Entretiempo", la indicación manuscrita de su nuevo destino: "En la rama del verde limón”. El tercero, como ya comenté más arriba, es un recorte de texto impreso, sin indicaciones de procedencia o destino.

En cualquier caso, en los once poemas, a partir de las peculiaridades materiales de los borradores conservados, podemos reconstruir un similar proceso de trabajo. Juan Ramón tomaba composiciones de otros libros para destinarlos a uno nuevo en proyecto, En la rama del verde limón. Después anotaba bajo el borrador del poema su procedencia. Asimismo, en el transcurso de este proceso, releía el poema, y en algunos casos lo sometía a leves correcciones. Un trazo manuscrito idéntico al de estas correcciones (en cuanto al útil de escritura, pluma estilográfica, y al tipo de letra) es el que encontramos en los papeles en los que Juan Ramón diseña el interior del libro. A diferencia de otros proyectos inéditos que personalmente he estudiado en otras ocasiones, en los que encontramos materiales procedentes de fases de redacción muy alejadas en el tiempo, en esta ocasión todo hace pensar que el material hallado en el sobre 106 pertenece a un periodo de tiempo corto y concreto, pudiéndose fechar en torno a 1919-1920.

Debemos preguntarnos ahora acerca de la procedencia de este material reutilizado por Juan Ramón para la construcción de un nuevo proyecto de libro. Según las indicaciones que nos da el autor, los poemas son extraídos de los siguientes libros: La frente pensativa, La corriente infinita, Luz de la atención, La realidad invisible, Piedra y cielo, El vencedor oculto, Entretiempo y La torre abierta. Es importante advertir en este punto que ninguno de ellos, excepto Piedra y cielo, que se había publicado en 1919, había visto la luz, ni se publicaría nunca como tal libro. Algunos de ellos fueron parcialmente representados en las antologías del poeta: La frente pensativa lo fue en la Segunda antolojía poética (1922); mientras que Luz 
de la atención, La realidad invisible y El vencedor oculto aparecieron en Poesía (1923) y Belleza (1923). Entretiempo fue anunciado y parcialmente representado en la revista España (1920), y da noticia de La torre abierta en el libro Eternidades (1918).

En segundo lugar, habría qué preguntarse que hizo Juan Ramón posteriormente con los materiales destinados a En la rama del verde limón. Y ahora conviene señalar que si el proyecto del libro es inédito, lo cierto es que ninguno de los poemas a él destinados lo es. Al margen de las publicaciones parciales del libro en revistas o en uno de los cuadernos, que ya hemos señalado, los once poemas se imprimieron también en otros libros del poeta, aunque no lo hicieran bajo el título de En la rama del verde limón. "Pájaro del sueño rosa..." se publicó en Bellaza (64), con el título "Canción de desvelo". "He venido..." se publicó en Poesía (119), con el título "El pajarito verde". "No me mirarán diciendo..." se publicó en Poesía (129), sin la referencia a "James Stephens" y sin la variante del verso 6. "Muy tarde" se publicó en Poesía (102), con una variante en el verso 7: "sueño alto". "Nostaljia" se había publicado en Piedra y cielo (110), en 1919. "Verde es la nińa..." se publicó en 1936 en Canción (108), con el título "La verdecilla", en versión corregida y ampliada. "Mis ojos abiertos..." se publicó en Poesía (86), con el título "El desvelado" y, también, en versión corregida y ampliada. “¿Espera, ratito de oro,...” se publicó en Poesía (44), en idéntica versión. "En estas redes finas...” se publicó en Poesía (35), en idéntica versión. "Alrededor de la copa..." se publicó en Poesía (1), en idéntica versión. "Me escondí en el arbusto..." se publicó en Canción (399), con el título "Hoja y agua”. Comparadas unas y otras versiones, creo poder afirmar que las copias halladas en el sobre 106 y referidas a En la rama del verde limón son anteriores a las que encontramos en las publicaciones Poesía, Belleza o Canción. En otro sitio ${ }^{13}$ ya expliqué que rara vez Juan Ramón en su proceso corrector reduce el tamaño de un poema; más bien tiende a alargarlo con la incorporación de nuevas estrofas. Por ejemplo, las significativas variantes que muestra el poema "Mis ojos abiertos" con respecto a la versión publicada en Poesía, me inclinan a pensar que la versión destinada a La rama del verde limón es anterior.

13 Teresa Gómez Trueba, op. cit., p. 119. 
Las antologías Poesía y Belleza se publicaron ambas precedidas de un idéntico listado de libros inéditos de los que se habían extraído los poemas: La realidad invisible, Unidad, Hijo de la alegría, Fuego y sentimiento, Luz de la atención, La mujer desnuda, Ellos, La muerte, Forma del huir, El vencedor oculto, La obra, 1920 (Miscelánea), 1921 (Miscelánea), 1922 (Miscelánea) y 1923 (Miscelánea). Pues bien, el aspecto laberíntico de este ir y venir de poemas de unos libros a otros se incrementa aún más cuando observamos que En la rama del verde limón no era uno de los libros supuestamente representados en las antologías Poesía y Belleza. Asimismo, algunos de los poemas seleccionados para En la rama del verde limón proceden de libros que tampoco estaban supuestamente representados en Poesía y Belleza, mientras que dichos poemas sí fueron después publicados en algunas de estas dos antologías: es el caso de "Pájaro del sueño rosa...", procedente de La frente pensativa; "He venido...", procedente de La corriente infinita; “Espera, ratito de oro...” y "En estas redes finas...” procedentes de Entretiempo; y "Alrededor de la copa...", procedente de La torre abierta. Por todo ello creo que es posible que en los intrincados planes editoriales juanramonianos los once poemas transcritos tuvieran un destino posterior al de En la rama del verde limón y anterior al de Poesía y Belleza. Y que, por tanto, existan también borradores de ellos que desconocemos, con una adscripción a otro libro intermedio ${ }^{14}$. Resumiendo, En la rama del verde limón es un proyecto de libro inédito que se forma con materiales procedentes en su mayoría de otros libros inéditos y que después pasaron a formar parte de unos terceros libros inéditos, de los cuales el poeta hizo entregas parciales en sus antologías.

Pero, ¿qué significado tiene este complejo trasiego de poemas de unos libros a otros, cuando, además, todos ellos eran libros inéditos y, por tanto, desconocidos para el lector? Veíamos más arriba que, a la hora de proyectar En la rama del verde limón, Juan Ramón había releído y corregido a mano los poemas a él destinados, pero que en realidad tenían muy pocas

14 Es posible que dichos borradores fueran los que sirvieron de originales para la imprenta cuando se editaron Poesía y Belleza. León Liquete advierte que "en relación con los libros de Juan Ramón editados hasta 1923 hay cierto vacío: Juan Ramón Jiménez subsumió en su archivo los borradores anteriores (y el original quedó en la imprenta) y las ediciones hicieron desaparecer el resto de borradores poco a poco" (La perdida, op. cit., pp. 57-58). 
correcciones, si comparamos estos borradores con los de otras épocas y proyectos, en los que las correcciones son constantes y abundantísimas. Cuando Juan Ramón decide hacer este libro, lo hace con materiales poéticos que ya han sufrido un previo proceso de corrección y depuración, y llegan aquí en versiones casi limpias de correcciones. En realidad, la mayor parte de las anotaciones manuscritas hechas en esa segunda fase redaccional que encontramos en los materiales analizados hacen referencia al título del libro del que procede el poema en cuestión. Todo parece indicar que, en el momento en el que Juan Ramón estaba proyectando el libro En la rama del verde limón, le importaba más marcar un cambio de destino para el poema que corregir este. Si comparamos, en cambio, algunas versiones de poemas adscritas a En la rama del verde limón, con las que se publicaron de ellos más tarde, en Poesía o Belleza, vemos que en algunos casos sí hay variantes significativas. Ello indica que estos poemas fueron releídos y corregidos de nuevo en una fase posterior, a la hora de preparar y publicar dichas antologías. Pero insisto en que no parecía ser esa su prioridad cuando organizó y agrupó los materiales de En la rama del verde limón.

Quiero destacar especialmente el hecho de que, de estos 11 poemas seleccionados por el autor para En la rama del verde limón, 10 contienen en el mismo borrador, anotado doblemente de su puño y letra, el título del libro del que proceden ${ }^{15}$. Adivino en Juan Ramón el interés por no ocultar esa procedencia, sino por resaltarla y con ello poner en evidencia la simultaneidad de ubicación para tales textos. Ello resulta llamativo cuando advertimos que los materiales de En la rama del verde limón, libro inédito, proceden de otros libros (La frente pensativa, La corriente infinita, Luz de la atención, La realidad invisible, El vencedor oculto, Entretiempo y La torre abierta), que también eran inéditos y que siguieron siéndolo. Cabría esperar que el proyecto de En la rama del verde limón, al nutrirse de materiales extraídos de estos otros, los anulara parcialmente, pero Juan Ramón nos demuestra que no es así, cuando se cuida de anotar puntualmente en los borradores el título del libro del que proceden cada uno de los textos. Es

15 He de recordar que de uno de ellos, el que comienza "¡Mis ojos abiertos...", nos falta el final, donde era de suponer que aparecería dicha indicación. Sabemos, en cualquier caso, que el poema procede del libro El vencedor oculto. 
decir, los mismos poemas existían, a veces en idéntica versión y otras en versión levemente alterada, en diferentes destinos.

\section{Conclusiones: "Yo CORRIJO ObRa, nO libros"}

A estas alturas de mi trabajo el lector puede tener la impresión de moverse a tientas por un confuso laberinto (quizás sin sentido ni salida) de títulos de libros y versiones de poemas. Intencionadamente he querido reflejar en mi trabajo la sensación de indescifrable caos que tiene cualquier investigador que se asome a los archivos del poeta. Pero algún sentido habría de tener todo ese complejo ir y venir de poemas de unos libros a otros en la concienzuda y meticulosa mente de nuestro autor.

A partir del análisis genético de los materiales arriba transcritos, hemos podido comprobar que, en el caso que nos ocupa, el tiempo y trabajo que Juan Ramón dedica a diseñar materialmente el libro no es proporcional con el escaso material poético a él atribuido. Conocido es el cuidado de Juan Ramón Jiménez hacia las cuestiones editoriales, pero creo que ello no es explicación suficiente. El autor hace la cubierta del libro antes de escribir los poemas. No siempre obra así, pero en este caso está claro que el título o, lo que es lo mismo, el proyecto de libro, precede al libro propiamente dicho. Es más, este nunca llegó a escribirse, sino que se formó, en su integridad, a partir de materiales procedentes de otros libros en su mayoría también inéditos, pero que habían adquirido un mayor nivel de desarrollo o, al menos, contenían poemas expresamente escritos para ellos.

La obsesión juanramoniana por inventar proyectos se incrementa en esta época, al tiempo que decae el ritmo de publicación, quizás porque no siempre disponía del material suficiente para llenar esos proyectos. En este momento, Juan Ramón procede de manera distinta a cómo lo había hecho en épocas anteriores. Creo que, en los tiempos anteriores al Diario de un poeta recién casado (1916), escribía poemas sin cesar y cuando tenía un número suficiente de ellos formaba un libro que mandaba a la editorial. Progresivamente este hábito fue cambiando. Por las fechas en las que proyecta En la rama del verde limón, Juan Ramón se dedicaba sobre todo a inventar proyectos de libros, a partir del material ya escrito (y destinado 
a otros libros), que progresivamente iba revisando, y no escrito (pero que pensaba escribir) ${ }^{16}$.

A pesar del elevado número de libros proyectados por estas fechas y del escaso material en ocasiones a ellos adscritos, lo cierto es que cada uno de esos libros tenía en la mente de su autor una concreta identificación temática o formal respecto al resto. En el sobre 149 del AHN encontramos una serie de originales relativos a la proyectada serie de libros que iba a titularse Jardin menor. En casi todos los papeles de este sobre figura como uno de los libros de esta nueva serie el título En la rama del verde limón. Y en una de las notas dice textualmente: "Con estos títulos, con estas nuevas agrupaciones, defino sentidos de mi obra. No es una cosa caprichosa, ni industrial" (AHN, 149/4). Una cosa es que el lector sea incapaz de apreciar el sentido de tantas clasificaciones y subclasificaciones para la Obra, pero lo que sí parece claro es que para Juan Ramón sí había una idea determinada por debajo de cada uno de sus proyectos y todas esas clasificaciones tenían un sentido, más allá del mero interés editorial o comercial. El paso siguiente era agrupar poemas en torno a cada uno de los títulos inventados. Labor esta que no siempre concluía.

En cualquier caso, el relativo interés de este proyecto, o el hecho de que fuera en un momento dado importante para su autor, no nos deberían llevar a reconstruirlo y presentarlo como un libro de Juan Ramón Jiménez. No creo que sea honesto engordar la ya abundante bibliografía juanramoniana con un nuevo título, en cuyo interior se ofrecen una serie de poemas, que el lector ya conoce bajo otros títulos. Eso, que es lo que generalmente se viene haciendo, solo contribuye a complicar aun más el estado editorial actual. Sin embargo, sí debemos estudiarlo, ya que nos dice mucho de su concepción de la creación poética. En ocasiones se ha advertido que, aunque Juan Ramón tendió a corregir lo ya escrito desde sus inicios, la intensidad del proceso corrector se fue incrementando con

16 Quizás eso explicaría el diferente aspecto que, a primera vista, muestran los materiales agrupados en el AHN en torno a los libros inéditos representados en la Segunda antolojía poética, anteriores al Diario, por un lado, y en Poesía y Belleza, posteriores en su mayoría a 1917, por otro. En términos generales podemos decir que los materiales de los libros representados en estas segundas antologías muestra un aspecto mucho más limpio y ordenado que los de la primera, borradores confusos, llenos de tachaduras, múltiples versiones para cada poema, etc. 
el paso de los años ${ }^{17}$. Pero creo que la evolución en dicho proceso corrector la encontramos también en otro sentido, que va más allá de la mera intensidad correctora. El repetido aforismo juanramoniano "Yo corrijo Obra, no libros”, releído ahora a la luz de este análisis del proyecto En la rama del verde limón, nos pone sobre aviso acerca de una peculiaridad respecto a la legendaria manía correctora de nuestro autor. Esta, en determinados momentos, atañe más a un nivel macroestructural de la Obra, que a un nivel microestructural de poemas concretos. Creo que ese otro interés juanramoniano, el de la Obra por encima de las obras, se fue incrementando con el paso de los años, haciéndose especialmente visible en el proceso de creación del proyecto que hemos estudiado y en torno a las fechas en las que debió de fraguarse, o sea, a principios de los años veinte.

Pero para la permanente corrección de la Obra no siempre fue necesaria la escritura de nuevos textos. La relativa singularidad de En la rama del verde limón ${ }^{18} \mathrm{y}$, en mi opinión, su interés radican en que se forma, en su integridad, con materiales reciclados. Ello, por un lado, pone en evidencia una determinada forma de proceder en Juan Ramón, a la hora de construir sus libros, pero, sobre todo, nos está hablando de una determinada manera de concebir la Obra. Cada texto o cada libro, releídos tras un periodo de tiempo, adquieren otro significado que permite otra ubicación dentro de la misma. Iluminadoras a este respecto me parecen estas palabras de Hernández Alonso:

Para una línea muy definida de la poesía contemporánea -Valéry, Guillén- es consustancial a la idea de perfección estética la elaboración de orbes poéticos cerrados, limitados en las fronteras materiales de un volumen. Que Juan Ramón Jiménez era contrario a esta concepción unitaria y cíclica del poemario es evidente en su frenética actividad correctora, centrada en el poema concreto. El libro era para él receptáculo provisional, histórico, susceptible de posteriores selec-

17 Manuel Ángel Vázquez Medel, "Claves estilístico-textuales para el estudio del proceso creativo juanramoniano", en Actas del Congreso Internacional conmemorativo del centenario de Juan Ramón Jiménez, Huelva, Diputación de Huelva - Instituto de Estudios Onubenses, 1983, II, pp. 589-617 (p. 595).

18 Desde luego, En la rama del verde limón no es un caso aislado; otros muchos proyectos inéditos de Juan Ramón Jiménez se formaban en su integridad de materiales poéticos reciclados. 
ciones y refundiciones que buscan la reunión definitiva e intemporal de la Obra. [...] El texto poemático es, por un lado, resultado de un universo simbólico ya acuñado; por otro, embrión que crea nuevas expectativas de lectura de dicho universo ${ }^{19}$.

Por su parte, en un pionero trabajo, señalaba Vázquez Medel que, junto a las correcciones que surgen por sorpresa, existen otras, muy habituales en el proceso corrector de nuestro autor, que surgen a partir de un deliberado trabajo de revisión. La corrección realizada con cierta distancia temporal permite al autor contemplar el poema con cierta objetividad, como realidad exterior a sí mismo, a la que hay que volver a dotar de subjetividad $^{20}$. Cuado el autor revive el poema, lo dota, efectivamente, de un nuevo sentido que, naturalmente, no pretende anular el sentido originario que lo generó. Pero ese nuevo sentido es, sin duda, el que justifica en muchas ocasiones una reubicación nueva del texto en cuestión. Y es en este punto cuando debo advertir que, en mi opinión, la Obra no es para Juan Ramón solamente "Obra en marcha”, sino, como he intentado demostrar en otro trabajo, "Obra múltiple" 21 . Si no lo fue de una manera consciente desde el primer momento, sí lo era ya al menos por estas fechas. Al hablar de una "Obra múltiple" me refiero a que para Juan Ramón cada texto es susceptible de recolocación en otro contexto y, de esa manera, es también susceptible de una lectura diferente. La Obra encierra en sí misma diferentes, simultáneas y no incompatibles versiones de sí misma y por eso los poemas pueden ser sometidos por su autor a numerosas posibilidades de combinación. Creo que esta y no otra explicación es la que se esconde por detrás de tantos proyectos, tantos índices e indicaciones, solo aparentemente contradictorios.

19 Salvador Hernández Alonso, "Perspectivas críticas-horizontes infinitos. «La rosa viajera» de Juan Ramón: símbolos y proceso textual”, Anales de la literatura española contemporánea, 11 (1986), pp. 255-278 (pp. 255-256).

20 Manuel Ángel Vázquez Medel, op. cit., p. 592.

21 Teresa Gómez Trueba, "Juan Ramón Jiménez y su concepción de la Obra como una maquinaria poética combinatoria”, Artifara, 8 (2008), sección Monographica (http://artifara.com/) [en línea]. 